\title{
Brief tiered collaborative narrative intervention for kindergarten students: An exploratory study
}

\author{
Jessica E. Garzarek ${ }^{1,2}$, Rebecca Becknal', Jennifer A. Brown ${ }^{1}$ \\ ${ }^{1}$ Department of Communication Sciences and Special Education, University of Georgia, Athens, GA, ${ }^{2}$ Jessica Garzarek is now at Child'sPlay Therapy \\ Center in Hoover, AL, USA
}

\begin{abstract}
Purpose: Children enter school with varying levels of oral language skills and exposure to the narrative structure used in academic contexts based on individual, family, and environmental factors. Multi-tiered instructional models can be used to appropriately identify and support students who need intensive intervention while minimizing over-identification of students. The purpose of this increasing intensity study was to explore the clinical applicability of a tiered narrative language intervention for kindergarten students at-risk for academic difficulties.
\end{abstract}

Methods: Eleven kindergarten students who speak African American English (AAE) participated in a large group co-taught narrative language instruction. An increasing intensity design was used to identify treatment responders and treatment minimal responders. Minimal responders were provided individualized intervention.

Results: Eight students were characterized as responders to the large group instruction because of their increased narrative retell performance. Three students were minimal responders to the large group instruction and resultantly received a brief individualized intervention. Throughout the study, students improved their narrative language performance measured by story grammar, story episodes, and language complexity.

Conclusions: The feasibility of this collaborative narrative intervention with increasing intensity based on student response coupled with recent tiered narrative experimental studies is promising. Clinical implications of using multi-tiered narrative language systems in elementary school are discussed.

Keywords: Narratives, Child language intervention, Dialectal variations, Tiered models of support, Colloboration

\section{INTRODUCTION}

Collaborative tiered narrative intervention for at-risk kindergarten students

Early language and emergent literacy skills are predictive of subsequent academic success $[1,2]$. Children's oral narratives are important in understanding this relationship because limited narrative skills have been demonstrated to be predictive of poor language outcomes [3]. Narrative discourse bridges the gap between contextualized oral and decontextualized literate language and is foundational in the development of reading and writing skills [4]. Beyond its foundation in literacy, narrative discourse is an important component of oral language that is essential to the human experience. Stories allow us to build connections with the people around us, which influences social competence [5]. Children begin school with varying levels of oral language competency

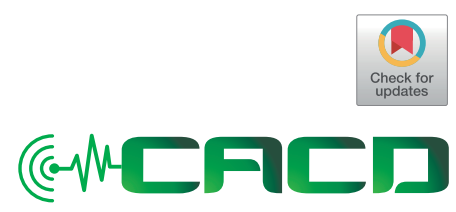

Received: September 18, 2019 Revision: December 6, 2019 Accepted: December 9, 2019

\section{Correspondence:}

Jennifer A. Brown

Department of Communication Sciences and Special Education, University of Georgia, 536 Aderhold Hall, Athens, GA 30602, USA

Tel: +7065429580

Fax: +7065425348

E-mail: jbrown8@uga.edu

(C) 2019 The Korean Association of SpeechLanguage Pathologists

This is an Open Access article distributed under the terms of the Creative Commons Attribution NonCommercial License (http://creativecommons.org/ licenses/by-nc/4.0/) which permits unrestricted noncommercial use, distribution, and reproduction in any medium, provided the original work is properly cited. 
and a wide range of exposure to literate language [6]. Environmental and family-specific factors - including emergent literacy experiences and socio-demographic variables - may place students at risk for language difficulties with a resulting negative impact on academic performance [7-9]. Students entering primary/elementary school have varying levels of experience with the narrative structure required in school [10], highlighting the need for identifying students who need differentiated explicit intervention to lead to better language and overall academic outcomes.

\section{Multi-tiered instruction and collaboration}

Multi-tiered instruction is a prevention and intervention framework for providing differentiated instruction according to the needs of each student. Worldwide, there are different models and initiatives for systematic differentiated instruction. In the US, Response to Intervention (RTI) is a tiered model designed to improve academic performance for students with and without disabilities and as a means to identify students with learning disabilities [11]. The tiered framework allows for systematic differentiated instruction with increasing intervention intensity and specialization in each tier (e.g., Tier 1 involves core instruction for all students; Tiers II and III involve additional evidence-based intervention provided more frequently and in smaller groups).

SLPs are increasingly providing more collaborative services $[12,13]$. Collaborative models allow SLPs to uniquely contribute to the language and literacy instruction provided in each tier [14]. Collaboration among SLPs and other school personnel can take many forms ranging from consultative to partnership approaches. Co-teaching is a collaborative service model that involves joint planning and instruction for students with and without language disorders in inclusive classrooms $[15,16]$. Providing collaborative classroom-based services is designed to support students' oral and written language skills throughout the day in functional and relevant contexts.

\section{Narrative language instruction}

Students with language disorders, at-risk for language disorders, and without identified language difficulties can benefit from explicit and systematic narrative instruction [17]. Elementary school students are expected to retell stories, identify characters, settings, and main events in a story as well as ask and answer questions about key details from a story [18]. A growing body of evidence supports the effectiveness of narra- tive instruction with a specific focus on explicit teaching of story grammar [19-21]. Retelling stories provides students with the opportunity to be an active participant in the reconstruction process, which reinforces the inclusion and appropriate sequencing of story grammar components.

Spencer and Slocum (2010) found measurable improvements of story retells in preschool students attending Head Start following a narrative intervention. The intervention focused on teaching story grammar in the context of story retell and story generation by using visual support, guided instruction, and story grammar identification games. Intervention was delivered in small groups and included linguistically and culturally diverse participants with and without language disorders. The students' story retells improved as a function of participating in the intervention. The gains demonstrate the effectiveness of providing small group narrative instruction to children with risk factors in addition to children with identified language disorders. Similarly, Brown, Garzarek, and Donegan (2014) implemented a narrative intervention in small groups of 4-year-old children with socioeconomic risk factors. In a multiple-baseline study across participants, effects of a multicomponent narrative retell intervention were measured by the inclusion of story grammar components in retells. This study extended previous narrative interventions by integrating an explicit guided self-monitoring component into the intervention package. The students took turns retelling a story that was recorded using an iPad application. Then, as the clinician played the recording of the student's retell, the students were instructed to listen for, identify, and graph the story grammar components. Students demonstrated measureable gains in inclusion of story grammar components in the production of narrative retells. These gains were maintained twoweeks after intervention was completed.

Until recently, most narrative intervention studies were conducted individually or in small groups. Large group and whole class interventions have the potential to increase language skills of students with varied learning needs. Gillam and colleagues (2014) compared the effects of the narrative intervention, Supporting Knowledge in Language and Literacy (SKILL), with embedded vocabulary instruction (experimental classroom) to business-as-usual reading and listening comprehension instruction (comparison classroom) on first grade students' storytelling and vocabulary. Prior to the intervention, students were characterized by low- and high-risk status based on macro-and micro-structure narrative skills. The experimental and control classrooms included a combi- 
nation of high- and low-risk students. Narrative instruction was integrated into the classroom schedule and included three phases: teaching of story grammar elements, story elaboration, and independent storytelling. Within each phase the SLP used story modeling, story retelling, story generation, and comprehension instruction to aid students' understanding of narration. Post-intervention assessments revealed a significant improvement in the narrative and vocabulary skills in the experimental classroom, suggesting the effectiveness of classroom-based narrative instruction. Further, the achievement gap between high-and low-achieving students diminished in the experimental classroom following the intervention but remained in the comparison classroom.

Spencer, Petersen, Slocum, and Allen (2015) examined the effects of the Story Champs multi-tiered language program on preschool students' story retells, story comprehension, and personal story generation in culturally diverse Head Start preschool classrooms. Researchers randomly assigned classrooms to Story Champs treatment and business-as-usual large group instruction comparison conditions. Retells and story comprehension scores were higher in the treatment condition immediately following the 3-week intervention. The statistically significant differences in narrative skills following a low-intensity intervention show promise for the effectiveness of whole class instruction for culturally diverse young children. Furthermore, the authors calculated responsiveness levels for the participating children to identify which children need additional intervention beyond the whole class instruction.

Responsiveness to narrative language intervention was extended in a study exploring a whole class narrative dynamic assessment to identify culturally and linguistically diverse preschool students in need of intensive narrative language intervention [22]. Students with limited response to the whole class test-teach-test dynamic assessment were randomly assigned to treatment or control conditions. The students in the treatment group received 18 sessions of small group Story Champs differentiated narrative intervention. The treatment group had significantly higher narrative retell outcomes, with large effect sizes, than the control group. These findings are particularly important in demonstrating the use of a tiered model of narrative language intervention.

\section{Current study}

This exploratory study builds on the use of large group/whole class narrative language instruction for culturally diverse stu- dents as means of identifying students who need more intensive intervention $[22,23]$ and on explicit self-monitoring as a narrative language intervention component [19]. A unique contribution of this examination is the extension to an older set of participants in a tiered narrative language intervention study. Previous tiered narrative language interventions have focused on preschool students, whereas, the participants in this study were in the first year of elementary school (i.e., kindergarten). Another distinctive feature of this study was the intentional collaborative co-teaching between speech and language SLP and classroom teacher for the large group instruction.

Large group narrative language instruction was provided to students in a kindergarten class in an urban school. The students who demonstrated minimal improvement to the large group instruction received subsequent brief individualized intervention. The exploratory research question was: How do kindergarten children who are at risk for academic and language difficulties respond to tiered narrative language intervention?

\section{METHODS}

\section{Participants}

All students $(n=11)$ enrolled in a single kindergarten classroom at a non-profit private school serving inner-city children in the Southeastern United States were selected as a convenience sample. The parents of the students provided informed consent and the students assented to participation. The whole class instruction in this study could be compared to RTI Tier 2 services that are typically provided in other US school contexts due to the small class size and students with demonstrated academic risk factors. Therefore, to promote applicability to other school settings, the whole class instruction in this study is referred to as large group instruction. The students were African American and eight were boys. At the start of the study, the average age of the students was 5 years, 3 months (range: 5 years, 0 month -5 years, 9 months). Students presented with one or multiple family risk factors including minority status, low-income families, single parent households, and subsidized housing. One student, Omar, had an identified expressive-receptive language disorder; the remaining students did not have an identified speech or language disorder. All students passed a hearing screening. All students spoke with a strong language variation consistent with African American English (AAE) as measured by the Diagnostic Evaluation of 
Language Variation-Screening Test (DELV-ST) [24] and clinical judgment. Students' language disorder risk status, as measured by the DELV-ST, ranged from low-to-high risk (lowest $n=3$; 9\% low-med $n=1$; med-high $n=2$; highest $n=5$ ). The Peabody Picture Vocabulary Test (PPVT; Dunn and Dunn, 2007) receptive vocabulary class mean was $94.81(\mathrm{SD}=10.52$; range $=79-108)$. The Test of Narrative Language [25] Narrative Language Ability Index class mean was 76 ( $S D=10.12$, range $=61-97$ ), demonstrating below average narrative skills in narrative comprehension and oral narration prior to instruction. The combination of language test performance, family socioeconomic variables, classroom academic performance, and limited use of the predominant dialect used in academic contexts placed the students at risk for poor language and academic outcomes. All students in the class participated in the large group instruction. Three students who were minimal responders to the instruction received a brief individualized intervention. Specific demographic information on those three students is provided in Table 1.

\section{Interventionists}

A Communication Sciences and Disorders graduate student (first author) with specific language and literacy training, the kindergarten classroom teacher, and a certified SLP were the narrative interventionists and data collectors for this study. The classroom teacher and graduate student implemented the full-class narrative instruction together two times a week using a co-teaching collaborative model. The classroom teacher continued narrative instruction independently on two other days each week to increase the intensity and to align with collaborative practices that can be implemented in typical settings. The graduate student independently delivered the individualized narrative intervention sessions. The SLP supervised the graduate student throughout the large group instruction and individualized intervention phases.

\section{Descriptive measures and materials \\ Diagnostic Evaluation of Language Variation-Screening Test (DELV-ST)}

The DELV-ST [24] is a standardized measure that assesses for and classifies linguistic variation that deviates from mainstream English, distinguishing normal dialectal variation from differences due to language delay or disorder. The DELV-ST was administered prior to the instruction phase to inform cultural differences when interpreting narrative structure differences and as a culturally responsive way to identify students at-risk for a language disorder.

\section{Peabody Picture Vocabulary Test-Fourth Edition (PPVT-4)}

The PPVT-4 [26] is a standardized measure of receptive vocabulary skills. Students were administered the PPVT-4 prior to instruction to serve as a descriptive measure.

\section{Hearing screening}

A pure-tone audiometry hearing screening was conducted before inclusion in the study. All students were required to pass the hearing screening or have appropriate amplification to be included as research participants.

Table 1. Characteristics of participants

\begin{tabular}{|c|c|c|c|c|c|c|c|}
\hline Child & Age & Sex & Race & $\begin{array}{c}\text { TNL } \\
\text { standard score }\end{array}$ & $\begin{array}{c}\text { PPVT-4 } \\
\text { standard score }\end{array}$ & $\begin{array}{c}\text { DELV-ST } \\
\text { language risk }\end{array}$ & $\begin{array}{c}\text { DELV-ST } \\
\text { language variation }\end{array}$ \\
\hline Jadah & $5 ; 5$ & $\mathrm{~F}$ & African American & 97 & 105 & Lowest & Strong \\
\hline Martin & $5 ; 3$ & M & African American & 88 & 100 & Lowest & Strong \\
\hline Antwon & $5 ; 4$ & $M$ & African American & 82 & 98 & Highest & Strong \\
\hline Elliot & $5 ; 2$ & $M$ & African American & 79 & 108 & Highest & Strong \\
\hline Alisha* & $5 ; 5$ & $\mathrm{~F}$ & African American & 76 & 80 & Low to Med & Strong \\
\hline Lamon & $5 ; 9$ & M & African American & 73 & 86 & Med to High & Strong \\
\hline Trevor & $5 ; 5$ & $M$ & African American & 73 & 106 & Med to High & Strong \\
\hline Derrick & $5 ; 1$ & $M$ & African American & 70 & 92 & Highest & Strong \\
\hline Ava* & $5 ; 0$ & $F$ & African American & 70 & 102 & Lowest & Strong \\
\hline Kembe & $5 ; 3$ & $M$ & African American & 67 & 87 & Highest & Strong \\
\hline Omar* & $5 ; 5$ & $M$ & African American & 61 & 79 & Highest & Strong \\
\hline
\end{tabular}

*Ava, Alisha, and Omar each demonstrated minimal response to the large group instruction and subsequently were provided individualized intervention. 


\section{Test of Narrative Language (TNL)}

The TNL [25] is a standardized measure of narrative discourse skills, including story comprehension, retell, generation, and sequencing. Administration of the TNL occurred pre-instruction for all students to serve as a comprehensive measure of students' narrative discourse skills.

\section{Instructional materials}

We used the same adapted stories as used in the Brown et al. (2014) study. Each fictional story came from a common early elementary book and was adapted to clearly represent the targeted story grammar components. Digital pictures of key scenes from each story were printed on $3 \times 4$ in cards and used as story pictures. A complete set of story pictures was provided to each student as part of the retell activities. A list of the stories will be provided via request. We used picture icons from the Supporting Knowledge in Language and Literacy program (SKILL) [27] to represent the story grammar components. The icons were printed on 2x2in cards, displayed electronically on the Smartboard, and were printed on self-monitoring checklists.

\section{Dependent measure}

We administered the Test of Narrative Retell (TNR) subtest from the Narrative Language Measures (NLM) [28] throughout the study to provide a consistent measure of narrative language performance. The TNR retell probes consist of short stories without pictures that have similar narrative structures. Standardized administration begins with the examiner instructing the child, "I'm going to tell you a story. Please listen carefully. When I'm done you are going to tell me the same story. Are you ready?" The examiner reads the narrative, and then says, "Thanks for listening. Now you tell me that story." Each narrative retell was audio-recorded and scored according to the NLM procedures. The total score combines performance in three areas: story grammar, episode, and language complexity. Story grammar elements (character, setting, problem, emotion, plan, attempt, consequence, ending, and ending emotion) are scored on a 0-2 scale. Combinations of story grammar elements to represent the story's plot are scored in a weighted manner as episode (plot+attempt, plot+consequence, or attempt+consequence $=2$ points; plot + consequence + end ing or plot+attempt+ending $=3$ points; plot+attempt+ consequence $=4$ points; plot + attempt + consequence + ending $=5$ points). Frequency of temporal and subordinating conjunctions (then, because, after, when) is tallied to represent lan- guage complexity. The primary dependent variable in this study was the TNR total score. Additionally, the story grammar, episode, and language complexity subtotals were used to measure students' progress.

The third author administered the TNR probes to each student individually in a quiet classroom across the hall from the students' primary classroom. The examiner administered three TNR probes, each on separate school days within one week, to each student before and after the large group instruction. For the three students participating in the brief individualized intervention, the examiner administered four TNR probes individually to each student on the school day (or two days after, if the child was absent on the next day) following the intervention session. Additionally, we administered three follow-up TNR probes, each on separate school days within one week, six weeks after completing the individualized intervention.

\section{Study design}

An increasing intensity design was used to evaluate the amount of intervention needed to improve students' narrative language performance specifically in the area of retelling stories. The successive treatment intensity was replicated across three children who responded minimally to large group instruction. Given that participants had the same number of baseline, or pre-intervention, data points, experimental control was not demonstrated. Instead, this design illustrates progress monitoring and data-based decision making that is clinically relevant to providing tiered interventions in school settings [29].

\section{Procedure}

\section{Large group instruction}

The graduate student and classroom teacher used a collaborative co-teaching model to plan and implement the instruction. We shared thoughts, ideas, expectations, and concerns throughout the development and implementation of the narrative instruction via meetings, email, and informal conversations. For example, we discussed the classroom schedule, structure, and narrative instruction goals and plans prior to beginning instruction. We made decisions on how to incorporate the instruction into the existing classroom structure to decrease the potential negative impacts of disrupting the routine. The teacher provided important insight on the classroom dynamics and individual student performance as well as contributed to the learning outcome goals for the class. Through 
the collaborative planning process, we identified the idea of a puppet show to potentially increase student engagement and to provide another story grammar identification opportunity. The instructors continued to communicate, plan, and problem solve together (e.g., how to ensure each student has an opportunity to answer questions during story time) throughout the narrative instruction implementation.

We delivered 13 large group instruction sessions over three weeks during the class reading block (week 1: 4 sessions; week 2: 5 sessions; week 3: 4 sessions). Each session lasted approximately 30 minutes and only one session was provided per day. The graduate student and classroom teacher collaboratively delivered two sessions per week and the teacher delivered the other sessions independently. The narrative instruction approach was adapted from the SKILL program [27] and focused on systematic explicit teaching of story grammar and modeling the use of connecting and transitional vocabulary (e.g., because, so, but, then, after). Following an introduction to narrative structure on day one, explicit instruction (definition and focused identification) of story grammar elements were taught sequentially. Although only one story grammar element was explicitly taught per session, all elements were modeled in the telling and retelling of stories. On the first day of instruction, the instructors addressed the concept that stories follow similar structures and are comprised of various parts. We explained that each of the story grammar icons represent parts of a story as the respective icons were displayed on the classroom SmartBoard. The narrative instruction followed a similar structure as Brown et al. (2014) and can be divided into phases: before the story, during the story, and after the story.

\section{Before the story}

The instructors opened the session by verbally defining the targeted story grammar component, modeling a representative gesture (e.g., gesture for take-off (initiating event) is palms together rising in the air mimicking a rocket taking off), and displaying the corresponding icon on the SmartBoard. Students were asked to chorally repeat the definition and gesture. The instructors provided examples of the component and asked the students to come up with their own examples. One instructor acted out a short story with puppets. The other instructor identified the targeted component in the puppet show to provide a model for the students. On subsequent days, the instructors asked the students to identify the component in the puppet show. After all story grammar components were introduced, instructors began sessions by reviewing each component (e.g., asking students to name, define, identify, and show the gesture for each component).

\section{During the story}

The instructors reminded the students of the targeted story grammar component definition and instructed them to raise their hands if they heard the component during the storybook reading. One of the instructors read a story with pictures. When students raised their hands, the instructor paused the reading and said, "I see a hand raised. Did you hear the takeoff? Remember, a take-off is what gets the story going. It could be a problem, a surprise, or something that the character wants or needs." The instructor either repeated the correctly identified story grammar element or provided a corrective model if a child did not produce the correct response. As the number of components specifically targeted expanded, the instructors asked the students to listen for and identify each component.

\section{After the story}

After the story, the instructors displayed the story grammar icon on the Smartboard and modeled the representative gesture while asking the students to identify the story grammar component(s) within the storybook. A least to most prompt system was used to elicit targeted responses: (a) repeat the story grammar component definition; (b) provide picture cue by displaying corresponding story picture from book; (c) provide a verbal choice between responses; and (d) model desired response. The instructors used clinical judgment to determine the specific starting prompt within the hierarchy for each student. The instructors passed out a set of story pictures to each student while instructing them to individually sequence the pictures in the order of the story. The instructors walked around the room providing assistance to the students in sequencing the story pictures (e.g., "Did he make lemonade or buy lemons next?"). Once the pictures were ordered, the instructors asked the students to take turns retelling the story to their partner (i.e., the student sitting across from them at their table). The instructors walked around the room and provided feedback to the students by expanding their stories while emphasizing the targeted story grammar elements. After the partner retell, the instructors concluded the lesson by defining each story grammar component again, modeling a complete retell, and guiding the class in a large group retell.

\section{Brief individualized intervention}

Students who were minimal responders to the large group in- 
struction were provided a brief individualized intervention. This level of intervention could be compared to a Tier 3 support. Characteristics of the minimal performers, Ava, Alisha, and Omar, included: (a) small TNR total score gains in comparison to the class average gain; (b) post-instruction total TNR average scores lower than 8; and (c) post-instruction average score of zero on the episode subtotal. See Table 1 for descriptive characteristics of the brief individualized intervention participants.

\section{Sessions}

Four one-on-one, 30-45 minutes intervention sessions over the course of two weeks were conducted individually with Alisha, Ava, and Omar. The sessions were individualized to match each student's narrative skills. Similar to the large group instruction, the intervention continued to focus on explicit teaching of story grammar components. Students practiced receptive identification of story grammar components and retelling stories. In addition, goal setting and self-monitoring training were incorporated to encourage independence and facilitate the application of these skills. The key elements of this intervention are described below.

\section{Self-monitoring and goal setting}

Each session began with an audio-recorded TNR progressmonitoring story, which informed the focus of instruction for that session. These TNR retells were not used for dependent variable measurement. The purpose of the TNR retell at the beginning of each intervention session was to provide a consistent story structure as context for the student to self-monitor and set goals. Following the standard administration of the TNR, the interventionist reviewed the story grammar components by presenting the definition, icons, gestures, and assisting the student in identifying these pieces in the TNR retell. This review primed the students for the self-monitoring exercise. Students were instructed to listen for the story grammar elements in their own retelling (the TNR retell) as it was played back to them. Each time the student identified a story grammar element in the replay it was marked on the corresponding space of the self-monitoring checklist. The student had an opportunity to independently identify the component. The interventionist guided this process if the student missed or incorrectly labeled a story grammar element. Specific guidance included the following prompts: pausing the recording and instructing the student to listen again, pointing to the corresponding icon, providing the definition of the story gram- mar element, and problem solving by asking questions (e.g., "Who was in the story?" "Did you say that in your story?"). This process was intended to teach self-monitoring skills by listening for the inclusion of story grammar components in story retells. Once the self-monitoring checklist was filled out, the student graphed the number of story grammar components that were included in their retell. The data gathered from the self-monitoring checklist were used to create goals for future retells (e.g., "This time you included three story grammar elements. Next time let's see if you can include four") and to guide the focus of the remainder of the session.

\section{Story time}

The interventionist and student reviewed the story grammar elements that were left out of the TNR retell. The student was instructed to listen for these components in a picture book. Then, the interventionist read a picture book and guided the student in identifying the story grammar elements. The student retold the story using expansion and feedback from the interventionist to encourage the inclusion of all components.

\section{Social validity}

As a preliminary examination of acceptability of treatment outcomes, five undergraduate Communication Sciences and Disorders students who were blind to this study rated pairs of student retells for story completeness and coherence. The undergraduate students listened to six pairs of audio-recorded retells (three retell pairs from the large group instruction students and three retell pairs from individualized intervention students). For each of the six retell pairs, the undergraduate students listened to one randomly selected retell from the pre-large group instruction probes and one randomly selected retell from the post-large group instruction probes or individualized intervention assessment probes. The order of retells within each pair was presented randomly. The undergraduate students were instructed to select the retell within each pair that they judged to be "more complete and coherent." All five students rated each pair of retells with $100 \%$ correspondence to time point.

\section{Fidelity}

The third author measured fidelity of intervention procedures by completing a checklist consisting of key procedural components in $31 \%$ of large group instructional sessions and $33 \%$ of individualized intervention sessions. The 11-item large group instruction fidelity checklist included was separated into be- 
fore, during, and after the story categories. In the "before story" category, items addressed, verbally defining the targeted story grammar element, visually displaying the story grammar icon on the SmartBoard, asking children to define the story grammar element, and model story grammar element in a puppet show. The "during story" items addressed telling the children to raise their hands when they heard the story targeted grammar element, repeating the story grammar element definition, reading the story, and acknowledging when children raised their hand at the correct time or providing a prompt to do so. The "after story" items addressed facilitating a guided group retell, providing positive feedback and reviewing the story grammar element with the class, and expanding on children's retells by adding in additional components of the story. The 11-item individual intervention fidelity checklist addressed the following items: administers TNR, audio-records retell, gives student icon checklist and dry erase marker, names each story grammar element icon, instructs student to check off each element they hear, plays retell recording, gives feedback on selfmonitoring, reviews story grammar elements, reads story from picture storybook, asks student to retell story independently, and provides expansion and support during retell. Fidelity, as measured by inclusion of key procedural components, ranged from $81-100 \%$ with a mean of $91 \%$ for large group instruction and $100 \%$ for individualized intervention.

\section{Reliability}

A second rater independently scored $31 \%$ of the audio-recorded TNR retells over the course of the study to measure reliability of NLM scoring. Inter-rater reliability, as measured by percent agreement, ranged from $72-100 \%$ with a mean of $89 \%$.

\section{RESULTS}

\section{Large group instruction results}

The results from the large group instruction are presented in
Table 2. Students increased their narrative production over the course of the three-week instruction period demonstrated by a TNR total score gain of 5.15 points. Additionally, they demonstrated increased group means in all three subtotal domains. Students increased story grammar scores by 2.39 points, episode scores by 0.85 points, and language complexity scores by 2.0 points.

\section{Minimal responders}

Although the overall group means demonstrated an upward trend, Ava, Alisha, and Omar presented with clear patterns of minimal response. The minimal responders increased their mean TNR total score 2.45 points compared to the other eight students who demonstrated a 5.71 point mean increase. In addition to smaller gains, the three minimal responders had markedly lower ending scores compared to the eight responders, demonstrated by 10 point mean TNR total score difference between the two groups.

\section{Ava}

Ava scored a zero on the TNR before large group instruction. After large group instruction, she demonstrated a slight increase in use of story grammar components (pre-instruction $M=0.0$ to post-instruction $M=4.67$ ); however, she did not connect the story grammar elements together to form an episode. Her retells typically consisted of a single sentence with several restarts before saying, "I don't know." Additionally, she scored zero on language complexity before and after large group instruction.

\section{Alisha}

Alisha made gains on her TNR performance from pre- to postlarge group instruction (pre-instruction $M=2.67$ to post-instruction $M=7.67$ ), but did not form an episode in any retell. Alisha's retells were characterized by short facts of the story told out of order.

Table 2. Large group instruction results

\begin{tabular}{|c|c|c|c|c|c|}
\hline NLM & & TNR total & Story grammar & Episode & Language complexity \\
\hline \multirow[t]{2}{*}{ All students $(n=11)$} & Pre & $6.12(4.87)$ & $4.70(3.33)$ & $0.70(1.10)$ & $0.73(0.84)$ \\
\hline & Post & $11.27(5.82)$ & 7.09 (2.83) & 1.61 (1.69) & $2.70(1.93)$ \\
\hline \multirow[t]{2}{*}{ Responders $(n=8)$} & Pre & $7.96(4.44)$ & $6.04(2.82)$ & $0.96(1.19)$ & $0.96(0.86)$ \\
\hline & Post & $13.67(4.81)$ & $8.08(2.47)$ & $2.13(1.68)$ & $3.46(1.64)$ \\
\hline \multirow[t]{2}{*}{ Minimal responders $(n=3)$} & Pre & $1.22(1.56)$ & $1.11(1.27)$ & $0(0)$ & $0.11(0.33)$ \\
\hline & Post & $4.88(2.47)$ & 4.44 (1.94) & $0.22(0.67)$ & $0.67(0.87)$ \\
\hline
\end{tabular}




\section{Omar}

Prior to the large group narrative instruction, Omar's narrative retells on the TNR consisted of a single utterance with mention of one incomplete story grammar component. After large group instruction, Omar typically included one complete story grammar element (pre-instruction $M=1.0$ to post-instruction $M=2.33$ ). He regularly repeated the last line of the story.

\section{Individualized intervention results}

Ava, Alisha, and Omar's narrative language performance are visually depicted in Figures 1, 2, and 3. Each of the three children's response to increasing intensity of intervention is demonstrated as phase changes marked by dashed lines: pre-large group instruction, large group instruction, post-large group instruction, individualized intervention, and follow-up. The first graph for each student depicts the total TNR score. The graphs below depict the individual subtotals: story grammar, episode, and language complexity. Overall, the students increased their narrative language performance and maintained their skills after the intervention was completed. It is important to interpret these results in the clinically relevant manner of the design and not to make casual claims.

\section{Ava}

Ava quickly learned the process of self-monitoring and appeared motivated by setting goals and monitoring her own performance. In the individualized intervention phase, she increased use of complete story grammar elements and connected the key elements to form episodes. Ava's retells primarily consisted of short sentences with limited language complexity; however, she began using "then" as a temporal coordinating conjunction. Ava maintained similar levels six weeks after the brief individualized intervention in all areas, with an increase in her episode score.

\section{Alisha}

Alisha quickly learned the self-monitoring strategies, appeared to motivated by her progress, and demonstrated increased confidence in retelling stories (e.g., began immediately when asked instead of needing several prompts to start). She accurately evaluated her own performance at the conclusion of the intervention. Alisha made a steep increase in narrative language performance at the start of the individualized intervention. She used several complete story grammar elements and combined them together into three-element epi- sodes. She expanded her language complexity by using different conjunctions to connect phrases. Alisha's narrative production in the follow-up probes was similar to the intervention probes across all measured components demonstrating maintenance of skills.

\section{Omar}

Omar presented with the lowest narrative performance in the class after large group instruction. On the first day of individualized intervention, Omar demonstrated difficulty understanding the task and wh-questions were not helpful because of his limited understanding of such questions. Instead of presenting Omar with all of the story grammar elements, his intervention was simplified to focus on one element at a time. Additionally, the story grammar element visuals were used extensively throughout the intervention. Omar increased his use of story grammar elements and began including complete character and problem elements and occasionally incomplete or complete ending elements. The length of his retells increased, he began to use the conjunction "then," and he told the included elements in order. At the end of the intervention, he had not yet formed an episode. Omar demonstrated increased narrative production skills from the individualized intervention phase to the follow-up probes six weeks later. In the follow-up retells, Omar included more story grammar components and began connecting story elements together to form cohesive episodes.

\section{DISCUSSION}

We examined a tiered narrative language intervention for 5-year-old African American students in their first year of elementary school (US kindergarten). The participating students presented with several risk factors to meeting language expectations in formal academic settings, including linguistic variation of high density African American dialect, low average to below average language performance assessment results, and family socioeconomic risk factors. Students were already in a small class $(n=11)$ designed to provide high quality education with a low teacher-to-child ratio. This arrangement is comparable to some Tier 2 level instructional support arrangements. All students received a three-week class wide large group narrative language intervention co-taught by a graduate speech and language interventionist and their classroom teacher. Eight students increased their retell performance to include basic to complete episode structures. Three students did not 

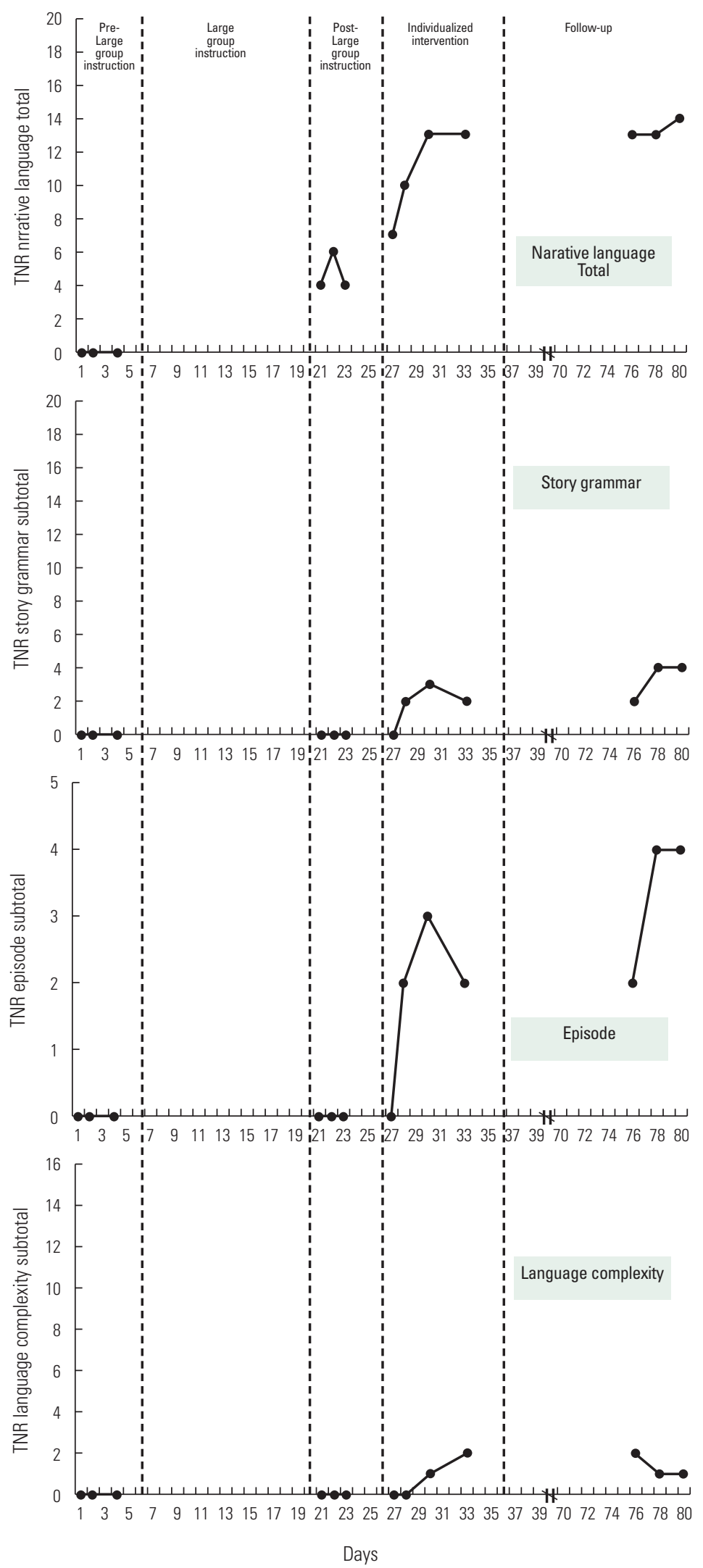

Figure 1. Ava's response to an increasing intensity narrative language intervention. 
Garzarek JE, et al. Collaborative narrative intervention
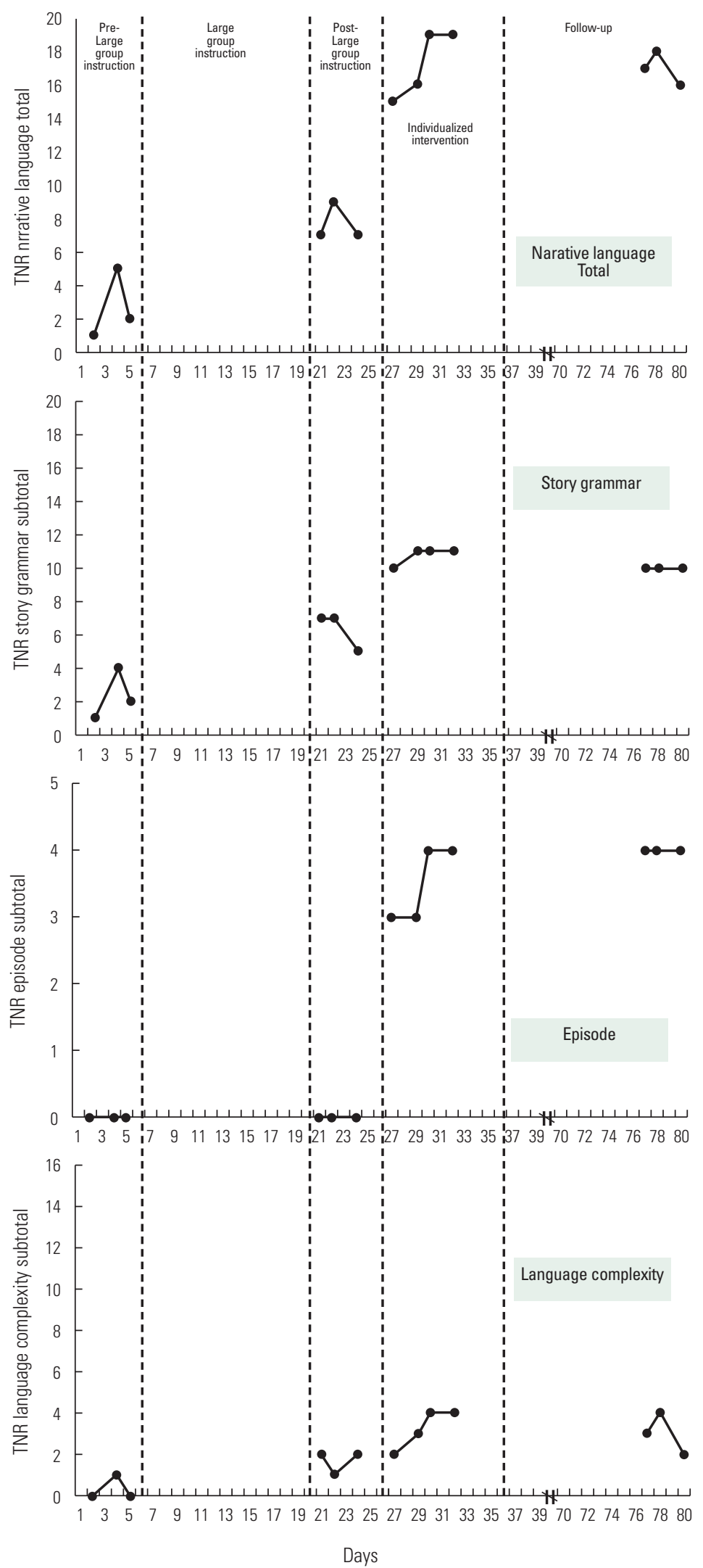

Figure 2. Alisha's response to an increasing intensity narrative language intervention. 

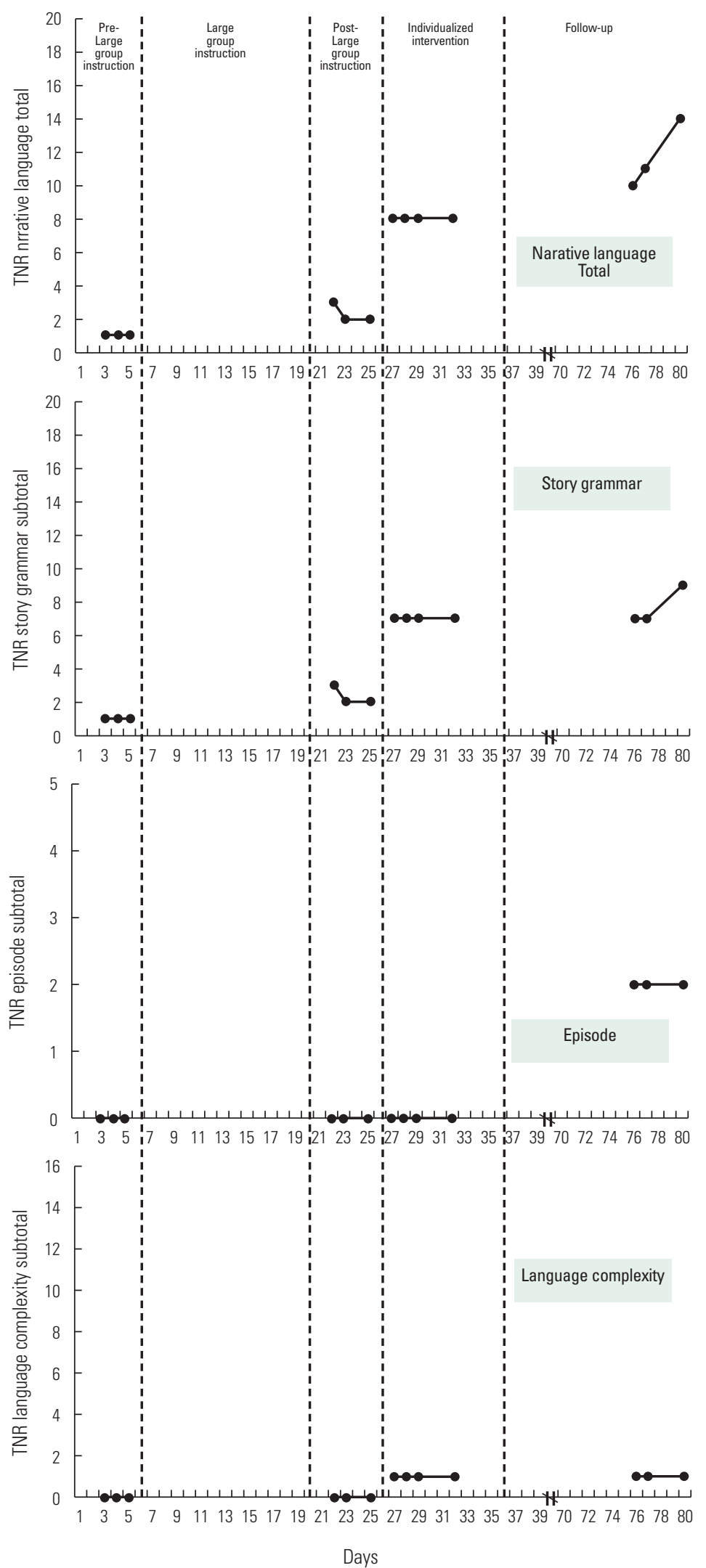

Figure 3. Omar's response to an increasing intensity narrative language intervention. 
make comparable retell gains and received individualized intervention modeled after a brief Tier 3 intervention.

Exploratory results from this increasing intensity study add further support for narrative intervention for children from culturally and linguistically diverse backgrounds as well as provide a clinically applicable extension to collaboratively delivered tiered supports for school-age students. Although this study does not report experimentally controlled findings, the students' increased narrative language performance follow similar patterns to other well controlled individual and small group narrative intervention studies $[19,21,30]$. These results show promise for examining large group narrative instruction in school-age children as a way to provide language instruction for all students and to contribute to efforts in identifying students needing additional intervention. This study extends the clinical applicability of tiered preschool narrative intervention study results $[22,23,31]$.

\section{Multi-tiered Instruction and Collaboration}

Multi-tiered systems of language support provide a way to promote language skills in children needing additional experience with academic language as well as to identify children needing more intensive intervention and identify students with learning disabilities [14,22]. SLPs' knowledge and skills in terms of language assessment and intervention can be of benefit to a wider range of students beyond those identified with language disorders. The need for skilled language assessment and intervention is especially important for minority racial and linguistically diverse students because of the challenges in accurately identifying culturally and linguistically diverse children with learning disabilities [32,33]. Although it rarely would be feasible or advisable for SLPs to provide direct services to all students needing Tier 2 instructional supports, they can collaborate with classroom teachers and other school professionals with good effect. There is a need for SLPs to have access to evidence-based, feasible, and acceptable collaborative tiered language and literacy interventions.

This study illustrates a clinical application of a tiered large group co-taught narrative language instruction and brief individualized intervention for students at-risk for not reaching or maintaining language and literacy standards. High quality evidence-based instruction and progress monitoring tools that appropriately demonstrate student response to instruction are crucial to the success of multi-tiered systems. Sensitive progress monitoring measures administered before and after high quality instruction can demonstrate a student's modifi- ability. This dynamic assessment approach (i.e., test-teachtest) can assist in identifying children who may have learning disabilities and children with language performance that was modifiable in the process. For the former students, tiered language systems may aid in earlier identification of learning disabilities yielding timely intervention. For the latter students, tiered language systems may decrease overidentification of learning disabilities in children who simply needed additional language experiences. As the evidence is expanding for tiered narrative language supports for preschool students [22,23,31], it is important to extend this line of research to school-age students. Exploring effective progress monitoring and instructional practices is critical for clinical implementation in school settings.

We administered a subtest of the NLM to have a standardized measure of inclusion of narrative language performance. School SLPs and related professionals may be particularly interested in this assessment because it provides opportunities for brief consistent standardized narrative language probes which can serve screening and/or progress monitoring functions. The NLM shows promise for an efficient and effective dynamic assessment tool to differentiate levels of response to narrative instruction. Since this study's implementation, the authors of the NLM have expanded it as part of a larger language and decoding screening and progress monitoring assessment, CUBED: Decoding, Language, Reading [28]. The CUBED includes NLM Listening, NLM Reading, and Dynamic Decoding Measures to assess listening retell, comprehension, vocabulary, personal narrative generation, decoding fluency, reading retell, phonemic awareness, word identification, and decoding. In the current study, we used what is now the listening retell portion of the CUBED NLM Listening.

\section{Narrative instructional practices}

We used several instructional components that are consistently included across narrative intervention studies. Previous research suggests having students produce gestures while teaching a skill promotes retention of that skill [34] and some narrative intervention studies include gestures [22,23]. We paired gestures and visual icons with story grammar component names and definitions. Gestures and icons were embedded into all activities. Students easily learned the gestures and readily showed them when prompted (e.g., "Show me character"). After all story grammar components were introduced, we reviewed the entire sequence of gestures and icons while discussing the connections between story grammar elements 
to facilitate comprehension of the story grammar structure. Active practice with receptive identification and generative retells was a central focus in each lesson. In the current study, we used a modification of established narrative instructional procedures and added components (e.g., puppet show) based on collaborative discussions with the classroom teacher. Given the increasingly robust evidence for established curricula, such as Story Champs [35] and SKILL [27], there is limited need for SLPs to develop or adapt narrative interventions as we did in this study. Both curricula can be used in large group, small group, and individual contexts. Story Champs is clearly aligned with multi-tiered language instruction. Future research should focus on the effectiveness of these curricula in RTI contexts with students older than preschool age.

\section{Brief individualized intervention}

Individualized intervention sessions included self-monitoring and goal setting training to further promote acquisition, generalization, and maintenance of story grammar knowledge. Brown et al. (2014) found positive student gains in students' inclusion of story grammar elements using a guided selfmonitoring strategy in their multi-component narrative intervention. We extended the clinical applicability of these findings by explicitly teaching self-monitoring and goal setting within the context of story grammar instruction. Students initially required maximum support to identify story grammar elements in their retells. Support faded across sessions for Ava and Alisha, but Omar required maximum support throughout the individualized sessions.

It is important to recognize the brief nature of the individualized intervention sessions. In only four sessions over two weeks, all three children made progress in their narrative language performance. Alisha maintained similar narrative production levels in the follow-up session and Ava and Omar demonstrated slight improvement in at least some of the measured narrative language skills. Ava demonstrated a slight increase in story grammar components with a more noticeable increase in episodic structure. Omar made the most noticeable improvements in his narrative production subsequent to the end of the individualized intervention. He went from an absence of retell episodic structure to consistently using basic episodic cohesion in the follow-up probes. These improvements could be due to maturation, classroom instruction, and/or additional exposure and experience with narrative structure in stories. It would have been interesting to see how additional individualized intervention sessions would have impacted each of the students' performance. Extending the length of the individualized language intervention is likely necessary to more substantial improvement.

\section{Limitations and implications}

The most significant limitation of the current study is the nonexperimental study design. Therefore, findings should be interpreted through the perspective of a clinical exploration. Limitations in the actual instructional approach include adapting existing curricula by adding instructional components without doing a controlled examination of the adaptations. For example, the added puppet show may have not contributed to students' learning. That time could have been more effectively spent engaging in an evidence-based language intervention component. The length of the large group instruction and individualized intervention was brief. Future research examining duration, dosage, and intensity would be beneficial.

Future narrative intervention research should examine empirically studied narrative language intervention as a tiered language support for elementary school students. Exploring this approach with students with varied profiles, including cultural and linguistically diverse students, may contribute to more effective identification of learning disabilities and preventive language support to children needing academic language experiences. More so, controlled studies of large group narrative dynamic assessment procedures to identify students in need of more intensive language intervention are important. Given the multicomponent nature of narrative language intervention, researchers should examine individual components (e.g., self-monitoring, gestures) to identify active ingredients for efficient intervention.

Clinical implications from this study include an emphasis on the role of SLPs in preventive practices, collaborative coteaching, making data-based decisions to increase intensity of services and supports, and narrative language assessment and intervention. It is important for SLPs to take a proactive role in implementing evidence-based progress monitoring and instruction practices within our expanded expectations to collaborate in the promotion of language skills for students with and without language disorders. Narrative language may be an appropriate area to begin that process. First, the predictive relationship between narrative language and academic performance illustrates the need for and importance of improving narrative language skills for all students. Second, there are established manualized evidence-based curricula 
(e.g., Story Champs) and standardized progress monitoring tools (e.g., CUBED) that can be practically implemented within various school contexts including tiered systems, large group, small group, and/or individualized intervention. Third, narrative language addresses curricula needs of students that both classroom teachers and SLPs are responsible for promoting. This shared context, coupled with manualized intervention materials, may support initial collaboration efforts. Additionally, the increasing intensity design used in this study can easily be implemented in clinical settings to make treatment decisions for individual students. Making data-based decisions on when to increase or intensify services and the subsequent impact on student learning is a necessary component of providing evidence based language intervention. SLPs are well suited to provide and support meaningful narrative language skill development within preventive and treatment services for students with and without language disorders in school settings.

\section{REFERENCES}

1. Catts HW, Fey ME, Zhang X, Tomblin JB. Estimating the risk of future reading difficulties in kindergarten children: a researchbased model and its clinical implications. Language, Speech, and Hearing Services in Schools. 2001;32:38-50.

2. Roth FP, Speece DL, Cooper DH. A longitudinal analysis of the connection between oral language and early reading. The Journal of Educational Research. 2002;95:259-272.

3. Bishop DV, Edmundson A. Language-impaired 4-year-olds: distinguishing transient from persistent impairment. Journal of Speech and Hearing Disorders. 1987;52:156-173.

4. Westby CE. Assessing and remediating text comprehension problems. Language and Reading Disabilities. 2005:157-232.

5. Bliss LS, McCabe A. Personal narratives: Assessment and intervention. Perspectives on Language Learning and Education. 2012;19: 130-138.

6. Cabell SQ, Justice LM, Konold TR, McGinty AS. Profiles of emergent literacy skills among preschool children who are at risk for academic difficulties. Early Childhood Research Quarterly. 2011; 26:1-14.

7. Scarborough HS, Neuman S, Dickinson D. Connecting early language and literacy to later reading (dis) abilities: Evidence, theory, and practice. Approaching difficulties in literacy development: Assessment, pedagogy and programmes. 2009;10:23-38.

8. Hoff E. Interpreting the early language trajectories of children from low-SES and language minority homes: implications for closing achievement gaps. Developmental Psychology. 2013;49:4.

9. Zill N, West J. Entering Kindergarten: A Portrait of American Children When They Begin School. Findings from the Condition of Education, 2000. 2001.
10. Terry NP, Mills MT, Bingham GE, Mansour S, Marencin N. Oral narrative performance of African American prekindergartners who speak nonmainstream American English. Language, Speech, and Hearing Services in Schools 2013;44:291-305.

11. Fuchs D, Fuchs LS, Vaughn S. What is intensive instruction and why is it important? Teaching Exceptional Children 2014;46:13-18.

12. Justice LM. Evidence-based practice, response to intervention, and the prevention of reading difficulties. Language, Speech, and Hearing Services in Schools 2006;37:284-297.

13. Pampoulou E. Collaboration between speech and language therapists and school staff when working with graphic symbols. Child Language Teaching and Therapy 2016;32:361-376.

14. Ehren BJ, Montgomery J, Rudebusch J, Whitmire K. Responsiveness to intervention: New roles for speech-language pathologists. Retrieved http://www.asha.org/SLP/schools/prof-consult/NewRolesSLP/. 2006.

15. Hamilton-Jones B, Moore A. Ensuring high-quality inclusive practices: What co-teachers can do. Kappa Delta Pi Record 2013;49:156161.

16. Murawski WW. Co-teaching in the inclusive classroom: Working together to help all your students find success. WA: Institute for Educational Development. 2003.

17. Petersen D, Spencer TD. Narrative assessment and intervention: A clinical tutorial on extending explicit language instruction and progress monitoring to all students. Perspectives on Communication Disorders and Sciences in Culturally and Linguistically Diverse (CLD) Populations 2014;21:5-21.

18. National Governors Association Center for Best Practices \& Council of Chief State School Officers. Common Core State Standards for English Language Arts. Washington, DC: Authors. 2010.

19. Brown JA, Garzarek JE, Donegan KL. Effects of a narrative intervention on story retelling in at-risk young children. Topics in Early Childhood Special Education 2014;34:154-164.

20. Petersen DB. A systematic review of narrative-based language intervention with children who have language impairment. Communication Disorders Quarterly 2011;32:207-220.

21. Spencer TD, Slocum TA. The effect of a narrative intervention on story retelling and personal story generation skills of preschoolers with risk factors and narrative language delays. Journal of Early Intervention 2010;32:178-199.

22. Spencer TD, Petersen DB, Adams JL. Tier 2 language intervention for diverse preschoolers: An early-stage randomized control group study following an analysis of response to intervention. American Journal of Speech-Language Pathology 2015;24:619636.

23. Spencer TD, Petersen DB, Slocum TA, Allen MM. Large group narrative intervention in Head Start preschools: Implications for response to intervention. Journal of Early Childhood Research 2015; 13:196-217.

24. Seymour HN, Roeper T, deVilliers J, deVilliers PA. Diagnostic Evaluation of Language Evaluation: Screening Test (DELV-ST). San Antonio, TX: The Psychological Corporation 2003.

25. Gillam RB, Pearson N. Test of Narrative Language. Austin, TX: 
Pro-Ed 2012.

26. Dunn LM, Dunn DM. Peabody Picture Vocabulary Test, 4 th ed. Bloomington, MN: NCS Pearson 2007.

27. Gillam SL, Gillam RB, Laing C. Skill: Supporting knowledge in language and literacy, 2nd ed. Logan, UT: Utah State University 2012.

28. Petersen DB, Spencer TD. CUBED: Decoding, Language, Reading. Laramie, WY: Language Dynamics Group 2016.

29. Barnett DW, Daly III EJ, Jones KM, Lentz Jr FE. Response to intervention: Empirically based special service decisions from singlecase designs of increasing and decreasing intensity. The Journal of Special Education 2004;38:66-79.

30. Petersen DB, Spencer TD. Using narrative intervention to accelerate canonical story grammar and complex language growth in culturally diverse preschoolers. Topics in Language Disorders 2016;36:6-19.
31. Weddle SA, Spencer TD, Kajian M, Petersen DB. An examination of a multitiered system of language support for culturally and linguistically diverse preschoolers: Implications for early and accurate identification. School Psychology Review 2016;45:109-132.

32. Sullivan AL, Bal A. Disproportionality in special education: Effects of individual and school variables on disability risk. Exceptional Children 2013;79:475-494.

33. Wagner RK, Francis DJ, Morris RD. Identifying English language learners with learning disabilities: Key challenges and possible approaches. Learning Disabilities Research \& Practice 2005;20:615.

34. Cook SW, Mitchell Z, Goldin-Meadow S. Gesturing makes learning last. Cognition 2008;106:1047-1058.

35. Spencer TD, Petersen DB. Story Champs: A multi-tiered language intervention program. Laramie, WY: Language Dynamics Group 2012, 2016. 